include in the final questionnaire (named IBIS-Q; Table 1) having a sensitivity $84.4 \%$ and specificity $80 \%$ to detect SpA (AUC 0.8803 with $\mathrm{Cl}$ $95 \%$ 0.8305- 0.9301). We propose as cut-off of 4 positive questions of the IBIS-Q for SpA patient identification

Conclusion: IBIS-Q seems to be a useful and simple tool to use in our IBD clinic for the detection of SpA, with a good statistical performance. Further studies are needed to validate this questionnaire

Disclosure of Interests: llaria Tinazzi: None declared, Angela Variol: None declared, Antonio Marchetta: None declared, Andrea Geccherle: None declared, Pierluigi Macchioni: None declared, Dennis McGonagle Consultant for: Lilly, Novartis UCB, Speakers bureau: Lilly, Novartis UCB DOI:10.1136/annrheumdis-2019-eular.5887

\section{SAT0352 THE FREQUENCY OF OCULAR MANIFESTATIONS IN PATIENTS WITH ADULT VS. CHILDHOOD SPONDYLOARTHRITIS}

Matthew Turk ${ }^{1}$, Jacqueline Hayworth ${ }^{2}$, Tatiana Nevskaya ${ }^{1}$, Janet Pope ${ }^{1}$

${ }^{1}$ University of Western Ontario, London, Canada: ${ }^{2}$ University of Toronto, Toronto, Canada

Background: Adult spondyloarthritis $(\mathrm{SpA})$ is characterized by abnormal bone overgrowth and inflammatory erosive osteopenia in the spine. SpA may be associated with psoriasis and psoriatic arthritis (PsA), inflammatory bowel disease, reactive arthritis, enthesitis, and ocular features such as acute anterior iritis, and chronic uveitis. Juvenile SpA onsets in children under 16 years old and may present with more peripheral enthesopathies and arthritis than adult SpA.

Objectives: This meta-analysis investigated the frequency and type of ocular involvement in childhood and adult SpA. The difference in frequency between childhood and adult SpA was also investigated.

Methods: Medline, Web of Science and Cochrane databases were searched to September, 2018 to identify publications related to spondyloarthropathy (SpA), and ankylosing spondylitis (AS) with ocular conditions (OC) (conjunctivitis, keratoconjunctivitis sicca, xeropthalmia, uveitis, eye hemorrhage, optic neuritis, papilledema, orbital disease, retinal artery/vein occlusion, macular edema, retinitis, chorioretinitis, scleritis, iridocyclitits, choroid hemorrhage, blindness and amaurosis fugax). The rates of OC were extracted and random effects models estimated their frequency. Heterogeneity was evaluated using $\mathrm{I}^{2}$. Inclusion criteria were studies in SpA of either children or adults that included a frequency of OC. Differences in frequencies of $\mathrm{OC}$ between childhood and adult disease were compared using chi squared tests.

Results: The search process identified 3164 articles, of which 41 were eligible for inclusion. A pooled random effects model showed the prevalence of uveitis was $24 \%[20 \%-27 \%]$ in adult AS (23 studies, $N=11943$ patients), $10 \%[7 \%-14 \%]$ in adult PsA (9 studies, $\mathrm{N}=1817$ ), and $17 \%$ [10\%-24\%] in undifferentiated adult SpA (9 studies, 6568 patients). In juveniles with AS, the prevalence of uveitis was $27 \%$ [16\%-39\%] (8 studies, 927 patients). In child onset PsA, uveitis occurred in 16\% [10\%-21\%] (5 studies, $\mathrm{N}=498$ ), and in juvenile undifferentiated $\mathrm{SpA}$, uveitis had a frequency of $7 \%[1 \%-12 \%]$ (2 studies, $N=1531$ ). The differences in frequency of uveitis in adults vs. child onset SpA spectrum diseases were not significantly different between AS and JAS $(p=0.891)$, PsA and JPsA $(\mathrm{p}=0.732)$ and between $\mathrm{SpA}$ and JSpA.

Conclusion: This meta-analysis compares the frequency of ocular involvement in seronegative spectrum diseases in adults and children where it appears that the frequency of uveitis is not statistically different in adult vs. child onset SpA and the subsets.

\section{REFERENCES}

[1] Reveille JD, Weisman MH. The epidemiology of back pain, axial spondyloarthritis and HLA-B27 in the United States. Am J Med Sci 2013;345:4316.

[2] Smith JA. Update on ankylosing spondylitis: current concepts in pathogenesis. Curr Allergy Asthma Rep 2015;15:489.

[3] Stolwijk C, Essers I, van Tubergen A, Boonen A, Bazelier MT, De Bruin $\mathrm{ML}$, et al. The epidemiology of extra-articular manifestations in ankylosing spondylitis: a population-based matched cohort study. Annals of the Rheumatic Diseases 2015;74:1373-8.

[4] Lin Y-C, Liang T-H, Chen W-S, Lin H-Y. Differences between juvenileonset ankylosing spondylitis and adult-onset ankylosing spondylitis. J Chin Med Assoc 2009;72:573-80.

[5] Cantini F, Nannini C, Cassarà E, Kaloudi O, Niccoli L. Uveitis in Spondyloarthritis: An Overview. J Rheumatol Suppl 2015;93:27-9.
Disclosure of Interests: Matthew Turk: None declared, Jacqueline Hayworth: None declared, Tatiana Nevskaya: None declared, Janet Pope Consultant for: Eli Lilly and Company

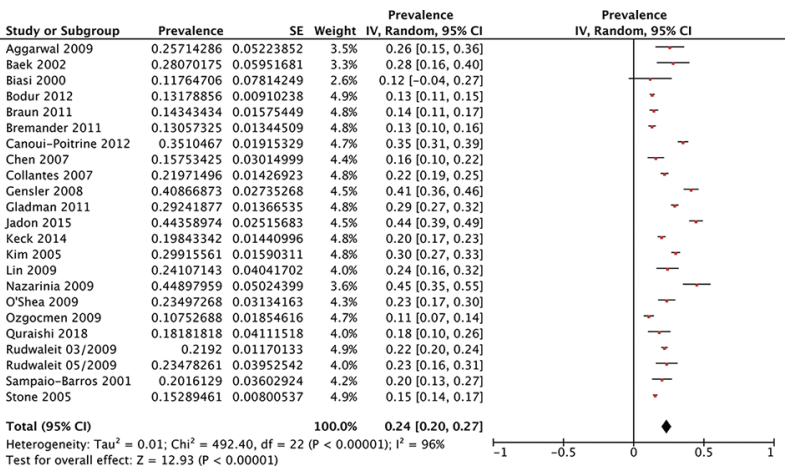

Figure 1. The frequency of ocular manifestations in adults with ankylosing spondylitis

DOI: 10.1136/annrheumdis-2019-eular.2434

\section{SAT0353 HIGH PREVALENCE OF NEWLY DIAGNOSED AXIAL SPONDYLOARTHRITIS IN PATIENTS WITH ACUTE ANTERIOR UVEITISAND CHRONIC BACK PAIN - PRELIMINARY RESULTS OF THE SP-EYE STUDY}

Rianne van Bentum ${ }^{1}$, Frank Verbraak ${ }^{2}$, Sanne Wolf ${ }^{2}$, Jenny Ongkosuwito ${ }^{3}$, Stevie Tan ${ }^{2}$, Irene van der Horst-Bruinsma ${ }^{4} .{ }^{1}$ Amsterdam Rheumatology and immunology Center, location Amsterdam University Medical Center VUmc, Amsterdam, Netherlands; ${ }^{2}$ Amsterdam University Medical Center, location VUmc, Ophthalmology, Amsterdam, Netherlands; ${ }^{3}$ Onze Lieve Vrouwe Hospital, Ophthalmology, Amsterdam, Netherlands; ${ }^{1}$ Amsterdam Rheumatology and immunology Center, location Amsterdam University Medical Center VUmc, Amsterdam, Netherlands

Background: One third of the axial spondyloarthritis (axSpA) patients suffers from acute anterior uveitis (AAU). Correspondently, AAU can be the first sign of axSpA and previous studies described undetected axSpA in up to $40 \%$ of the patients with noninfectious AAU.

Objectives: To study whether referral of all patients with AAU and chronic back pain results in a high prevalence of newly diagnosed axSpA patients.

Table 1. Patient characteristics at referral.

\begin{tabular}{|c|c|c|c|c|}
\hline & $\begin{array}{l}\text { Overall } \\
(\mathrm{N}=50)\end{array}$ & $\begin{array}{c}\text { Definite } \\
\text { AxSpA } \\
(\mathrm{N}=13)\end{array}$ & $\begin{array}{l}\text { Suspicion of early } \\
\text { axSpA }(\mathrm{N}=21)\end{array}$ & $\begin{array}{l}\text { No suspicion of } \\
\text { axSpA }(N=16)\end{array}$ \\
\hline Age & $42( \pm 13)$ & $44( \pm 15)$ & $38( \pm 9)$ & $45( \pm 15)$ \\
\hline Gender, men & $26(52)$ & $10(77)$ & $11(52)$ & $5(31)$ \\
\hline $\begin{array}{l}\text { Back pain } \\
\text { duration, years }\end{array}$ & $15(5-27)$ & $14(5-27)$ & $9(4-24)$ & $21(15-32)$ \\
\hline $\begin{array}{l}\text { Inflammatory } \\
\text { back pain }\end{array}$ & $21(42)$ & $9(70)$ & $9(43)$ & $3(19)$ \\
\hline$>1$ anterior uveitis & $26(52)$ & $9(69)$ & $12(57)$ & $5(31)$ \\
\hline HLA-B27 positive & $27(54)$ & $11(85)$ & $12(57)$ & $4(25)$ \\
\hline $\begin{array}{l}\text { SpA features } \\
\text { (ASAS) }\end{array}$ & $3( \pm 1)$ & $4( \pm 1)$ & $3( \pm 1)$ & $2( \pm 1)$ \\
\hline $\begin{array}{l}\text { SI joint } \\
\text { abnormality }\end{array}$ & $16(32)$ & $9(69)$ & $6(29)$ & $1(6)$ \\
\hline $\begin{array}{l}\text { Sacroilitis, } \\
\text { mNY criteria }\end{array}$ & $9(18)$ & $7(54)$ & $2(10)$ & $0(0)$ \\
\hline BASMI & $\begin{array}{c}2.4 \\
( \pm 2.4)\end{array}$ & $4.2( \pm 4.0)$ & $1.6( \pm 0.7)$ & $2.0( \pm 1.3)$ \\
\hline BASDAI & $3(2-5)$ & $2(2-4)$ & $3(2-5)$ & $3(2-5)$ \\
\hline $\begin{array}{l}\text { ASDAS-CRP } \\
>21\end{array}$ & $21(42)$ & $6(46)$ & $10(48)$ & $5(31)$ \\
\hline
\end{tabular}

Legend: Numbers are depicted as mean ( \pm SD), median (Q1-Q3) or number of patients (\%). Methods: A prospective ongoing observational study was started in April 2017, including all patients with noninfectious AAU and a history of back pain ( $\geq 3$ months, started < age of 45 years), referred from six Ophthalmology clinics to the Rheumatology Outpatient Clinic of the VU medical center. Patients with a known systemic disease associated with AAU were excluded. Patient characteristics, laboratory (HLA-B27, C-reactive 